\title{
A Review of Hybrid Indoor Positioning Systems Employing WLAN Fingerprinting and Image Processing
}

Review Paper

\author{
Firdaus Firdaus \\ Universitas Islam Indonesia, Faculty of Industrial Technology \\ Department of Electrical Engineering, Jl. Kaliurang, Yogyakarta, Indonesia \\ firdaus@uii.ac.id
}

\author{
Noor Azurati Ahmad \\ Universiti Teknologi Malaysia, Razak Faculty of Technology and Informatics \\ Department of Advanced Informatics, Jalan Sultan Yahya Petra, Kuala Lumpur, Malaysia \\ azurati@utm.my

\section{Shamsul Sahibuddin \\ Universiti Teknologi Malaysia, Razak Faculty of Technology and Informatics \\ Department of Advanced Informatics, Jalan Sultan Yahya Petra, Kuala Lumpur, Malaysia shamsul@utm.my}

\begin{abstract}
Location-based services (LBS) are a significant permissive technology. One of the main components in indoor LBS is the indoor positioning system (IPS). IPS utilizes many existing technologies such as radio frequency, images, acoustic signals, as well as magnetic sensors, thermal sensors, optical sensors, and other sensors that are usually installed in a mobile device. The radio frequency technologies used in IPS are WLAN, Bluetooth, Zig Bee, RFID, frequency modulation, and ultra-wideband. This paper explores studies that have combined WLAN fingerprinting and image processing to build an IPS. The studies on combined WLAN fingerprinting and image processing techniques are divided based on the methods used. The first part explains the studies that have used WLAN fingerprinting to support image positioning . The second part examines works that have used image processing to support WLAN fingerprinting positioning. Then, image processing and WLAN fingerprinting are used in combination to build IPS in the third part. A new concept is proposed at the end for the future development of indoor positioning models based on WLAN fingerprinting and supported by image processing to solve the effect of people presence around users and the user orientation problem.
\end{abstract}

Keywords - indoor positioning, image processing, orientation, people presence, WLAN.

\section{INTRODUCTION}

Location-based services (LBSs) are a significant permissive technology that has wide-ranging applications in our life [1]. LBS are services that combine geographic location with other information to provide more helpful services [2]. The LBS market is growing rapidly [3]; a market report estimates the LBS market to generate up to USD 77.84 billion revenue by 2021 [4]. One of the main components of LBS is the positioning system, which can be divided into indoor or outdoor. Global Navigation Satellite Systems (GNSS) have been used over a wide range of applications for outdoor positioning.

However, GNSS cannot be used for indoor positioning because GNSS signals are not strong enough to penetrate buildings. The failure of GNSS to work indoors has caused people to develop the Indoor Posi- tioning System (IPS) [5]. IPS-based service has great economic potential as well; a report estimates the global indoor location market to grow to $\$ 4,424.1 \mathrm{mil}-$ lion by 2019, as shown in Fig. 1 [6]. IPS is any system that gives a precise position inside of buildings, such as smart buildings [7], hospitals [8], airports [9], [10], subways [11], construction sites [12], industrial sites [13], and university campuses [14]. IPS utilizes many existing technologies such as radio frequencies (RFs) [15], images [16], magnetic fields [17], acoustic signals [18], as well as thermal [19], infrared [20], and optical [21][23] sensors together with other sensory information collected by a mobile device (MD) [24]. Examples of RF technology used in IPS, among others, are WLAN (Wireless Local Area Network) or Wi-Fi [25], [26], Bluetooth [27], Zig Bee [28], [29], RFID [30], frequency modulation (FM) [31], and Ultra-wideband (UWB) [32], [33]. 


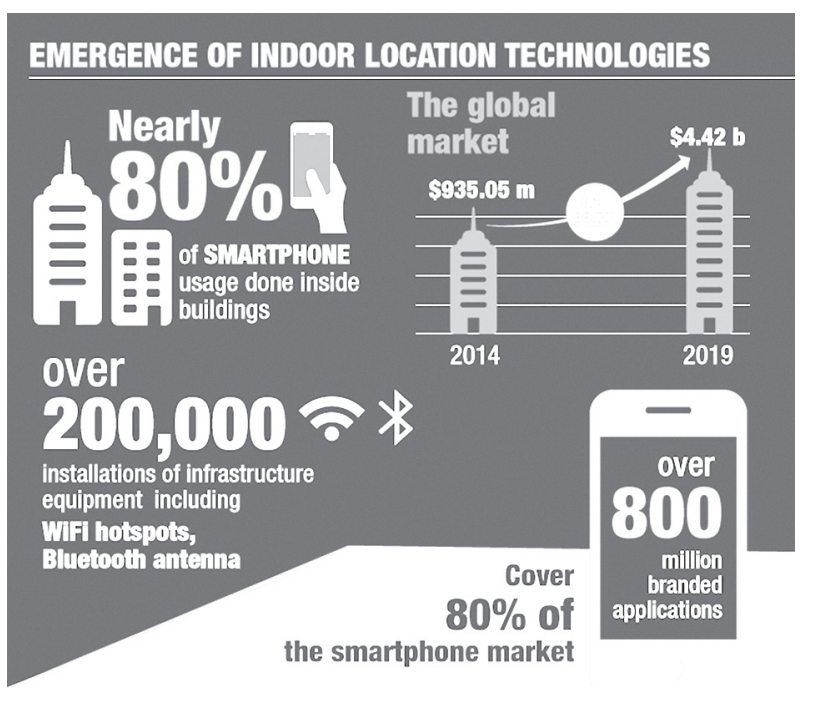

Fig. 1. Infographic on the future of IPS [6]

WLAN has been highlighted as a preferred technology due to its accurate positioning results and minimal infrastructure cost and power consumption [34], [35]. WLAN location detection techniques can be categorized into three general categories: proximity, triangulation, and fingerprint [15]. Fingerprinting is based on a pattern recognition technique that combines radio frequency (RF) with location information, e.g. an environmental label to show the position of the MD.

WLAN fingerprinting is usually conducted in two phases: offline and online. In the offline phase, a site survey is conducted to collect the value of the received signal strength indicator (RSSI) at many reference points (RPs) from all the detected access points (APs). Some researchers have proposed using indoor positioning technologies that do not require the construction of offline fingerprint maps [36] or just by updating the maps automatically [37]. In the online phase, a user samples or measures an RSSI vector at his/her position. Then, the system compares the received vector of RSSI with the stored fingerprints in the radio map (RM) database. The position is thus estimated based on the most similar "neighbors", i.e. the set of RPs with RSSI vectors that closely match the RSSI of the target [38]-[40].

Image-based object localization tries to detect the location based on image processing [16]. It has two main approaches [41]. The first approach tries to estimate absolute object localization. This approach performs object detection, object tracking, and 2D-3D mapping [42]. The second approach gives a coarse estimation of object localization based on scene analysis.

Silva et al. [43] discussed 62 review papers in the field of indoor positioning. Khalajmehrabadi [44] made a specific review on WLAN fingerprinting IPS. However, no one has specifically made a review of the hybrid method between WLAN fingerprinting and IPS image positioning. These two methods were chosen because both combined can provide high accuracy and could very possibly be cheaply implemented. This paper ex- plores the combination of WLAN fingerprinting and image processing for IPS. It discusses how this combination can improve location accuracy. Then, a new concept to enhance positioning accuracy is proposed.

Several studies have combined image processing with WLAN fingerprinting for IPS. In this review, the combination of WLAN fingerprinting with image processing is divided into 3 methods. The first part explained papers that have used WLAN fingerprinting to support image positioning. The second part consists of past work that has used image processing to support WLAN fingerprinting positioning. Then, the third part elucidates the works that have combined image processing and WLAN fingerprinting to build an indoor positioning system (IPS).

These methods are shown in Fig. 2. The first method is discussed in Section 2 while the second and third methods are discussed in Sections 3 and 4, respectively.

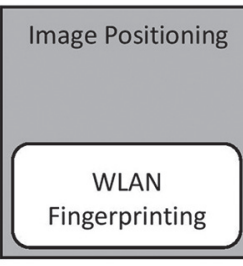

(a)

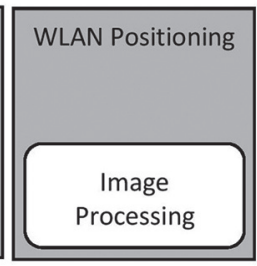

(b)

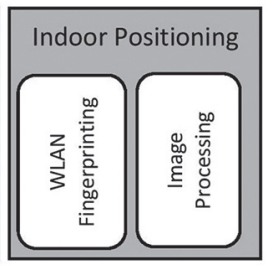

(c)
Fig. 2. The methods for image positioning, WLAN positioning, and Indoor positioning based on

(a) WLAN fingerprinting, (b) Image Processing,

(c) WLAN fingerprinting and Image Processing

\section{IMAGE POSITIONING SUPPORTED BY WLAN FINGERPRINTING}

In this method, image processing is used to determine position while WLAN Fingerprinting is used to support the process and improve system performance. Basically, this method is an image positioning or camera-based positioning technique that recognizes a location from an image taken of an indoor environment [21], [45]. Then, WLAN fingerprinting is used to improve the performance of the image positioning technique.

Ruiz [46] tried to find the location of some smartphones using the different sensors available in commodity smartphones. They used accelerometers, digital compasses, and $\mathrm{Wi}-\mathrm{Fi}$ signals to determine the smartphone position based on motion estimators, probabilistic techniques, and fingerprinting methods. Then, they used images from the smartphone camera to determine the correspondences between 2D and 3D. Ruiz et al. [47] continued their research using fingerprinting to determine an initial cluster with a high probability of showing the device location. Then, the matching process was automatically performed for these images contained in the selected cluster.

Savvas [48] proposed a new system that combined visual detection with radio readings. The visual detec- 
tion was captured using an available camera. This system is called Radio and Vision Enhanced Localization (RAVEL). RAVEL can improve the performance of visual trackers by overcoming issues such as occlusions and people entering/exiting the scene of visual detections.

Ito et al. [49] designed an IPS based on Wi-Fi and an RGB-D camera. First, they estimated a coarse global position using Wi-Fi fingerprinting and then computed a precise estimation using the data from the RGB-D camera based on the environmental floor plan.

Jiang [50] proposed a new method for indoor localization based on 3 parameters: Wi-Fi signal strength, orientation, and image. The main parameter was the image, while Wi-Fi signal strength and orientation were used to improve the technical accuracy and decrease the time required for image matching. They used Wi-Fi fingerprinting to determine an initial position, and then an inertial sensor to obtain user orientation. Finally, the user location was determined by matching candidate images with a certain tree image database, selected based on Wi-Fi signal strength and orientation.

Xiang [51] presented a pose estimation using 6-degrees-of-freedoms based on portable 3D visuals. First, in the offline phase, they built a 3D and signal strength model for an indoor environment. They then used a WiFi signal to locate the device in a 3D sub-model. Next, they applied feature matching between the onlinecaptured 2D image and the keyframe images to build a 3D model. Finally, the estimation process in the 3D domain was done using the iterative closest point (ICP) and the RANSAC algorithm.

Jiao [52] improved smartphone camera-based positioning using TC-OFDM (Time and Code Division Orthogonal Frequency Division Multiplexing). They developed FAST-SURF to compute a detailed location while reducing computational time at the same time. Speeded Up Robust Features (SURF) is a new invariant interest point detector and descriptor that is scalable and rotatable [53].

Wang et al. [54] proposed an indoor location that combined Wi-Fi signal and real-time images, as shown in Fig. 3. In the offline stage, Wi-Fi and image data were collected at the location via feature extraction application on the data. A total of $300 \mathrm{Wi}-\mathrm{Fi}$ fingerprints and 50 photos from different angles were collected at each sampling point. In the online stage, the Wi-Fi fingerprint acquired by the user's mobile phone was matched to obtain a rough position interval, then, the distance compensation and SURF point similarity matching of the real-time captured image were used to obtain the similarity with each pre-captured image, so that the coordinates of the sampling points corresponding to the most similar image could be obtained. However, the accuracy of the system was not mentioned.

The above-method was then improved by Wang et al. [55], who used AlexNet [56] to perform supervised learning classification modeling on the image for re- gional scoping in the online positioning stage. However, the position error was still quite high, at $2.2 \mathrm{~m}(90 \%$ of cumulative probability).

Off-line Acquisition Phase

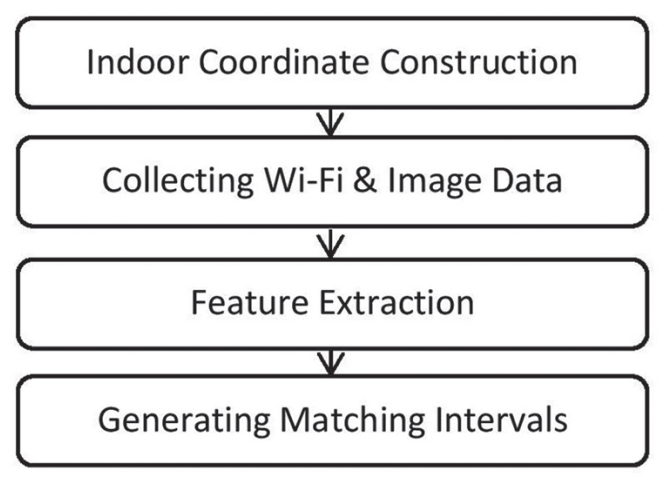

On-line Acquisition Phase

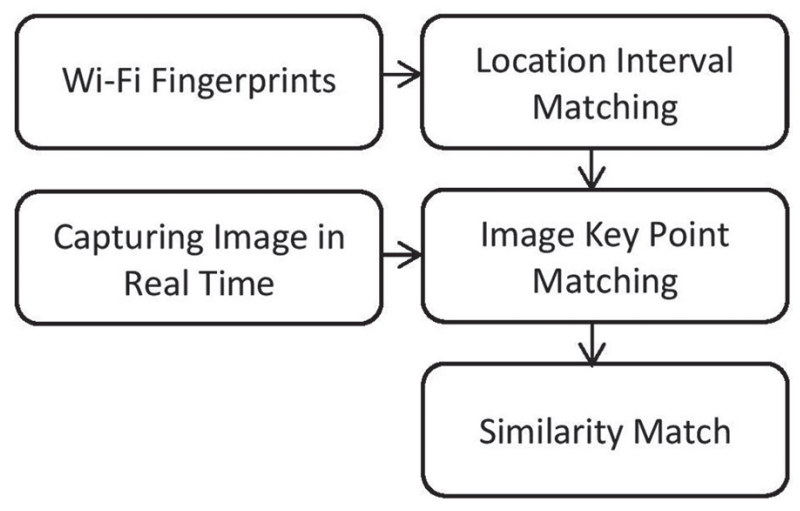

Fig. 3. Indoor location-based on Wi-Fi and image proposed by Wang et al. [54]

Simultaneous Localization and Mapping (SLAM) is an extensively researched topic in robotics. However, visual SLAM algorithms face several challenges including perceptual aliasing and high computational cost. Hashemifar [57] proposed a method to utilize Wi-Fi received signal strength to alleviate the challenges faced by visual SLAM algorithms, as shown in Fig. 4. The approach was able to improve the accuracy of visual SLAM algorithms by $11 \%$ on average and reduced computation time on average by $15 \%$ to $25 \%$.

To improve the accuracy of SLAM, the Wi-Fi signal strength and the RGB-D images had to be combined [58]. The Extended Karman Filter (EKF) employs the WiFi signal strength information to estimate the pose of a robot and the locations of the APs, while the graph-optimization part employs the RGB-D images to estimate the poses of the robot.

Image positioning techniques provide good accuracy. However, because they are based on image processing, these techniques require high computational power, processing time, and consume a lot of battery life. A list of past research related to Image Positioning Supported by WLAN Fingerprinting is shown in Table 1. 
Receive Wi-Fi signature and visual data

\begin{tabular}{|c|}
\hline Wi-Fi Clustering: \\
Find a Wi-Fi cluster that is similar to the \\
current Wi-Fi signature \\
\hline \\
Bounding Loop Closure: \\
Visually compare the cluster against \\
frames within similar Wi-Fi clusters \\
\hline \\
Assign the current frame to an available \\
cluster to create a new cluster
\end{tabular}

Fig. 4. A method to utilize Wi-Fi received signal strength using SLAM by Hashemifar [57]

Table 1. Research related to Image Positioning Supported by WLAN Fingerprinting

\begin{tabular}{|c|c|c|}
\hline Author (Year) & Algorithm \& Performance & Device \\
\hline $\begin{array}{l}\text { Ruiz et al. [46] } \\
\qquad(2012)\end{array}$ & $\begin{array}{l}\text { - } \mathrm{kNN}, \mathrm{SIFT} \\
\text { - A mean error of } 15 \mathrm{~cm}\end{array}$ & Phone camera \\
\hline $\begin{array}{l}\text { Ruiz et al. [47] } \\
\qquad(2013)\end{array}$ & $\begin{array}{l}\text { - } \mathrm{kNN}, \mathrm{SIFT} \\
\text { - } \text { Reduced the search time by } \\
\text { up to } 25 \%\end{array}$ & Phone camera \\
\hline $\begin{array}{l}\text { Papaioannou } \\
\text { et al. [48] } \\
\text { (2014) }\end{array}$ & $\begin{array}{l}\text { - A median error of } 0.56 \mathrm{~m} \\
\text { - A } 90 \text {-percentile error : } 1 \mathrm{~m}\end{array}$ & CCTV \\
\hline $\begin{array}{l}\text { Ito et al. [49] } \\
\text { (2014) }\end{array}$ & - RANSAC & RGB-D camera \\
\hline $\begin{array}{l}\text { Jiang and Yin } \\
\text { [50] (2015) }\end{array}$ & $\begin{array}{l}\text { - Euclidean distance, SIFT } \\
\text { - The accuracy was } 96 \%\end{array}$ & Phone camera \\
\hline $\begin{array}{l}\text { He et al. [51] } \\
\qquad(2016)\end{array}$ & $\begin{array}{l}\text { - SIFT, RANSAC } \\
\text { - The average error was } 10 \mathrm{~cm} \\
\text { (translational) \& } 8 \text { degrees } \\
\text { (rotational) }\end{array}$ & $3 \mathrm{D}$ visual sensor \\
\hline $\begin{array}{l}\text { Jiao et al. [52] } \\
\qquad(2016)\end{array}$ & $\begin{array}{l}\text { - FAST-SURF } \\
\text { The accuracy was } 0.823 \mathrm{~m} \\
\text { (horizontal) \& } 0.5 \mathrm{~m} \text { (vertical) }\end{array}$ & Phone camera \\
\hline $\begin{array}{l}\text { Wang et al. } \\
\text { [54] (2018) }\end{array}$ & $\begin{array}{l}\text { - SURF } \\
\text { - No information about the } \\
\text { system accuracy was pro- } \\
\text { vided }\end{array}$ & Phone camera \\
\hline $\begin{array}{l}\text { Wang et al. } \\
\text { [55] (2019) }\end{array}$ & $\begin{array}{l}\text { Used AlexNet to perform } \\
\text { supervised learning classifi- } \\
\text { cation modeling } \\
\text { - The position error was } 2.2 \mathrm{~m}\end{array}$ & Phone camera \\
\hline $\begin{array}{l}\text { Hashemifar et } \\
\text { al. [57] (2019) }\end{array}$ & $\begin{array}{l}\text { - Visual SLAM } \\
\text { - Improved the accuracy by } \\
11 \% \text { on average }\end{array}$ & Camera \\
\hline $\begin{array}{l}\text { Yang et al. [58] } \\
\qquad(2018)\end{array}$ & $\begin{array}{l}\text { - Extended Karman Filter } \\
\text { - Graph-optimization }\end{array}$ & RGB-D \\
\hline
\end{tabular}

\section{WLAN FINGERPRINTING POSITIONING SUPPORTED BY IMAGE PROCESSING}

In this method, WLAN Fingerprinting was used to determine the position whereas image processing was used to support the process and improve performance. Mirowski [59] built a navigation robot using multiple sensors, including signal strength (RSSI) and odometry. He used image processing in the offline phase to construct a physical map of a building. In the online phase, WLAN fingerprinting was used to determine the location.

Ching [60] proposed a new framework based on Wi-Fi Localization and image processing. The system consisted of client and server components. The client-side consisted of three modules: Camera, Wi-Fi Scanner, and Gyroscope. The server consisted of four modules: Image Feature Extraction, Wi-Fi Localization, Image Feature Comparison, and Database Search. The study used JOpenSurf to extract and compare image features. JOpenSurf is a variation of the SURF (Speeded Up Robust Features) method in Java. The precision of this method was $94 \%$ - less than $5 \mathrm{~m}$-and the accuracy was $1.64 \mathrm{~m}$.

Niu [61] also proposed WLAN and image combination for IPS, similar to the solution given by Ching [60], but did not use a gyroscope. The study demonstrated that by using the proposed method, they were able to reduce the search time by up to $83 \%$, but it did not mention the error position.

Hou [62] used the RANSAC algorithm for AP selection in the online stage. Hou's [62] solution did not use images but instead used an algorithm usually used in image processing. The method was able to filter and remove the APs impacted by environmental variation. As a result, not only was the amount of calculation reduced but also the positioning accuracy was improved. The average error of the positioning system was 1.63 $\mathrm{m}$, and the minimum error was $0.76 \mathrm{~m}$.

Ali et al. [63], [64] used image processing and loT sensors (ESP8266 module) in the offline stage to generate and update a radio map database automatically. They used WLAN Fingerprinting to find the position. The experimental results showed that the proposed system achieved an average accuracy of $2 \mathrm{~m}$.

Travi-Navi [65] captured images and collected Wi-Fi samples and IMU-sensed data to pack them into navigation traces, as these traces can be shared with the user directly or through a cloud server. To achieve this aim, some lightweight trace-merging algorithms were employed in the study to discover the overlapping segments and merge multiple traces. Gu et al. [63] proposed an indoor localization system that combined Wi$\mathrm{Fi}$ and magnetic fingerprinting, image-matching, and people co-occurrence (WAIPO). A list of past research into WLAN Fingerprinting Positioning supported by Image Processing is shown in Table 2. 
Table 2. Research related to WLAN Fingerprinting Positioning Supported by Image Processing

\begin{tabular}{|c|c|c|}
\hline Author & Algorithm \& Performance & Device \\
\hline $\begin{array}{l}\text { Mirowski et al. [59] } \\
\qquad(2012)\end{array}$ & $\begin{array}{l}\text { - SLAM } \\
\text { - Median accuracy: } 5.2 \mathrm{~m} \\
\text { (in a } 54 \mathrm{~m} \text { corridor) }\end{array}$ & RGB-D sensors \\
\hline $\begin{array}{l}\text { Ching et al. [60] } \\
\qquad(2013)\end{array}$ & $\begin{array}{l}\text { - SURF } \\
\text { - Accuracy of } 1.64 \mathrm{~m}, \mathrm{a} \\
\text { precision of } 94 \% \text {, less } \\
\text { than } 5 \mathrm{~m}\end{array}$ & Phone camera \\
\hline Niu et al. [61] (2014) & $\begin{array}{l}\text { - Probabilistic Filter Model, } \\
\text { SURF } \\
\text { - Reduced the search time } \\
\text { by up to } 83 \%\end{array}$ & Phone camera \\
\hline Hou et al.[62] & $\begin{array}{l}\text { RANSAC algorithm for AP } \\
\text { selection in the online stage }\end{array}$ & $\begin{array}{l}\text { Image } \\
\text { Algorithm }\end{array}$ \\
\hline $\begin{array}{c}\text { Gu et al. } 2017 \text { [63] } \\
\text { (2017) }\end{array}$ & $\begin{array}{l}\text { - Wi-Fi and magnetic finger- } \\
\text { printing, image-matching. }\end{array}$ & Phone camera \\
\hline $\begin{array}{c}\text { Travi-Navi [64] } \\
\text { (2017) }\end{array}$ & - Wi-Fi and IMU & Server \\
\hline $\begin{array}{l}\text { Ali et al. } \\
{[65](2017),} \\
{[66](2019)}\end{array}$ & $\begin{array}{l}\text { - Image processing and loT } \\
\text { sensors } \\
\text { - Average accuracy of } 2 \mathrm{~m}\end{array}$ & $\begin{array}{l}\text { ESP8266 } \\
\text { module }\end{array}$ \\
\hline
\end{tabular}

\section{INDOOR POSITIONING BASED ON IMAGE PROCESSING AND WLAN FINGERPRINTING}

The combined WLAN and image processing techniques used data from RSSI, WLAN, and images to determine location. Usually, this technique has two databases, an RSSI database, and an image database. The initial method that combined Wi-Fi and camera was introduced by Hattori [67]. The study used a camera to get information from a two-dimensional marker placed on the floor. When they could not find the marker, they used Wi-Fi fingerprinting to define the marker's position. They used two types of fingerprints, RSSI from APs and RSSI from neighbor MDs (ad-hoc communication).

Nathan [68] introduced WHLocator, which provides location information based on three technologies: Wi$\mathrm{Fi}$, altimeter, and images. The Wi-Fi component was used to obtain MAC addresses and RSSI values from APs. Then, an algorithm was used to determine a list of possible locations. The location decision component requests data from the altimeter component and the scene analyzer to determine an estimated location. A scene classifier calculates the probability of a scene being a particular type. This method can be used to distinguish positions on the same floor that are difficult to distinguish based on fingerprints.

EV-Loc is another example of the same combination of techniques. Teng [69] proposed a localization technique called EV-Loc. They used a matching engine to find the correspondence between an electronic identifier (E) and its visual appearance (V). The visual signals improved the accuracy of the system. Levchev [70] combined a Wi-Fi fingerprint database and an image database to define location estimation. SIFT features were used for image processing. The average on-demand success rate was $86.3 \%$, higher than that of continuous capture (66.9\%). The mean error was 2.46 $\mathrm{m}$, the maximum error was $10.55 \mathrm{~m}$, and the standard deviation was $1.35 \mathrm{~m}$.

Bejuri [71] proposed an indoor positioning system based on wireless LAN and a camera. This method used grey-world-based feature detection and matching. The author also used a model fitting approach to combine the data from WLAN and the camera. First, the image was segmented and the corner detected. Then, a model fitting approach was used to match the point of interest in the image with the coordinated information and to get the location estimation. This method achieved a positioning accuracy of around $1.5 \mathrm{~m}$ in $22 \%$ of trials. Xu et al. [72] proposed Argus, an image-based localization system. This system works by extracting geometric constraints from crowd-sourced photos. Argus uses image and WLAN fingerprints to find the location inside a building. The study obtained the image from a smartphone camera by shooting a point of interest (POI) near their position. Then, they sent the image of the POI and the WLAN fingerprint to a server. The 80-percentile error was $1.38 \mathrm{~m}$ in the Mall and $2.30 \mathrm{~m}$ in the Plaza. The mean localization error using Argus was $1.29 \mathrm{~m}$.

In 2017, Jiau et al. [73] proposed a model that considered the effect of people. They proposed a new signal attenuation model to compensate for propagation loss, based on the population density. Image processing was used to detect a human body using a deep CNN [42] of local humans to which the number of humans was then calculated. This technique is based on Fully Convoluted Localization Neural Network (FCLN) architecture without the Recursive Neural Network language model to speed up the processing.

Then, they improved the positioning performance of the system by combining wireless signals and RGB images, as shown in Fig. 5 [74]. LBP is a local binary pattern. The proposed method was able to provide an accuracy of up to $0.83 \mathrm{~m}$ (RGB, Wi-Fi, and Bluetooth), and $2.88 \mathrm{~m}$ (RGB and Wi-Fi). However, the method requires significant time investment and effort in the offline stage, as well as a large amount of computing power in the online stage. Redzic et al. [75] presented an indoor localization system that combined both imagery and WLAN data to support a wide variety of location-based applications. The WLAN Localization component computes a location by matching the input RSS fingerprint against the fingerprint database. The Image Localization component compares the input image with the image database.

Then, the Fusion Engine employs the Thresholdbased component that combines the WLAN-based and image-based locations to output the final user location, as shown in Fig. 6. The study used an extended Naive-Bayes approach for WLAN Localization, and a hierarchical SURF (Speeded Up Robust Features) vocabulary tree of descriptors for Image Localization. The 
positioning error was $1.908 \mathrm{~m}$ for the particle filter and $1.904 \mathrm{~m}$ for the threshold-based engine. The average computational time was $5.68 \mathrm{~s}$ for the particle filter and $8.87 \mathrm{~s}$ for the threshold-based engine.

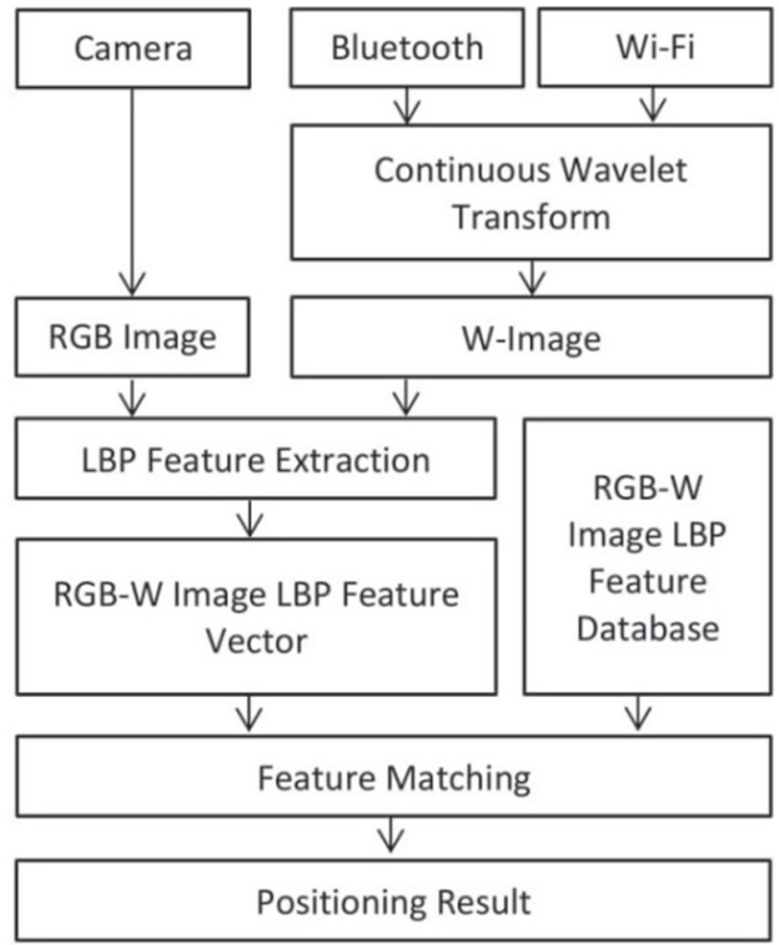

Fig. 5. Indoor location-based on wireless signals and RGB images by Jiao [74]

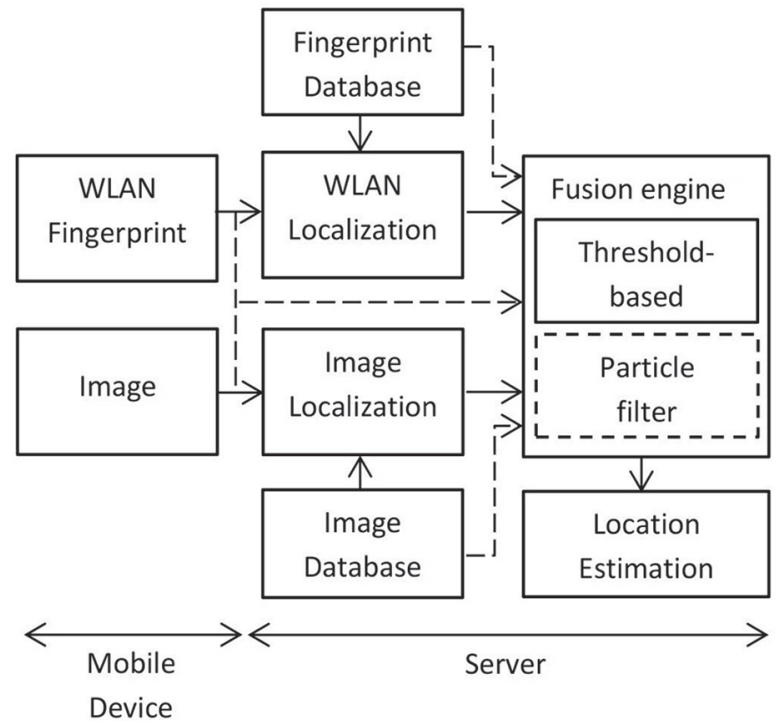

Fig. 6. Image and WLAN Localization by Redzic [75]

Jiao et al. [76] leveraged on a CNN framework and a particle filter to build a two-level high accuracy positioning architecture fusing on the image/Wi-Fi/magnetic/inertial. They proposed a new image named WMV, which fused 1-D signals (Wi-Fi/magnetic) with an RGB image. It was noted that the magnetic field, the image, and the inertial information were infrastructure-free and ubiquitous. The core of the fusion architecture was an im- proved four-layer deep neural network that integrated a Convolutional Neural Network (CNN) and an improved particle filter. The ubiquitous positioning accuracy of the proposed algorithm was less than $1.23 \mathrm{~m}$.

Image processing in combination with WLAN Fingerprinting provides good accuracy. However, these methods run both image matching and fingerprint matching, so more computational power and time are needed. For example, Argus consumed $171 \mathrm{~mW}$ additional power than the WLAN fingerprint method. A list of past research into Indoor Positioning based on Image Processing and WLAN Fingerprinting is shown in Table 3.

Table 3. Research related to Indoor Positioning based on Image Processing and WLAN Fingerprinting

\begin{tabular}{|c|c|c|}
\hline Author & Algorithm \& Performance & Device \\
\hline $\begin{array}{c}\text { Hattori et al. } \\
\text { [67] }\end{array}$ & $\begin{array}{l}\text { - Two types of fingerprints: RSSI from APs } \\
\text { neighbor MDs. }\end{array}$ & Phone \\
\hline $\begin{array}{l}\text { Nathan et } \\
\text { al. [68] }\end{array}$ & - A scene classifier & Phone \\
\hline $\begin{array}{l}\text { Teng et al. } \\
\text { [69] }\end{array}$ & $\begin{array}{l}\text { Matching engine to find the } \\
\text { correspondence between an electronic } \\
\text { identifier and its visual appearance. }\end{array}$ & Phone \\
\hline $\begin{array}{l}\text { Levchev } \\
\text { et al. [70] } \\
(2014)\end{array}$ & $\begin{array}{l}\text { - } \text { SIFT } \\
\text { - A mean error of } 2.46 \mathrm{~m}\end{array}$ & $\begin{array}{l}\text { Phone } \\
\text { camera }\end{array}$ \\
\hline $\begin{array}{l}\text { Bejuri and } \\
\text { Mohamad } \\
\text { [71] (2014) }\end{array}$ & $\begin{array}{l}\text { - Feature detection \& matching using } \\
\text { Grey-world } \\
\text { - Positioning accuracy was around } 1.5 \mathrm{~m} \\
\text { in } 22 \% \text { of trials }\end{array}$ & $\begin{array}{l}\text { Phone } \\
\text { camera }\end{array}$ \\
\hline $\begin{array}{l}\text { Xu et al. [72] } \\
\qquad(2015)\end{array}$ & $\begin{array}{l}\text { - } \mathrm{SfM} \\
\text { - The mean error was } 1.2 \mathrm{~m}\end{array}$ & $\begin{array}{l}\text { Phone } \\
\text { camera }\end{array}$ \\
\hline $\begin{array}{l}\text { Jiau et al. } \\
\text { [73] (2017) }\end{array}$ & $\begin{array}{l}\text { - Deep CNN } \\
\text { - A Fully Convoluted Localization Neural } \\
\text { Network }\end{array}$ & $\begin{array}{l}\text { Phone } \\
\text { camera }\end{array}$ \\
\hline $\begin{array}{l}\text { Jiau et al. } \\
\text { [74] (2018) }\end{array}$ & $\begin{array}{l}\text { - } 0.83 \mathrm{~m} \text { (RGB, Wi-Fi, and Bluetooth), and } \\
2.88 \mathrm{~m} \text { (RGB and Wi-Fi) }\end{array}$ & $\begin{array}{l}\text { RGB im- } \\
\text { ages }\end{array}$ \\
\hline $\begin{array}{l}\text { Redzic et al. } \\
\text { [75] (2019) }\end{array}$ & $\begin{array}{l}\text { - An extended Naive-Bayes approach for } \\
\text { WLAN Localization } \\
\text { - Hierarchical vocabulary tree of SURF } \\
\text { descriptors for Image Localization } \\
\text { - Positioning error was } 1.908 \mathrm{~m}\end{array}$ & $\begin{array}{l}\text { Phone } \\
\text { camera }\end{array}$ \\
\hline $\begin{array}{l}\text { Jiao et al. } \\
\text { [76] (2019) }\end{array}$ & $\begin{array}{l}\text { - Combination of images/Wi-Fi/ } \\
\text { magnetic/inertial } \\
\text { - Positioning accuracy was less than } \\
1.23 \mathrm{~m} \text {. }\end{array}$ & $\begin{array}{c}\text { RGB } \\
\text { image }\end{array}$ \\
\hline
\end{tabular}

\section{FUTURE DEVELOPMENT}

One of the performance indicators of IPS is accuracy, which is the error distance between the actual location and the estimated location. Many applications require precise IPS, among others, for emergency cases and patient monitoring. It is essential for the American emergency telephone number, 911, to know the location of the caller as precisely as possible to control delays in emergency response because delays in response can lead to a loss of lives. Therefore, 911 defined a new 
standard called "next-generation 911 (NG911)" [77], [78]. The US National Aeronautics and Space Administration Jet Propulsion Laboratory (NASA JPL) cooperated with the Department of Homeland Security Science and Technology Directorate (S\&T) to develop a precision outdoor and indoor navigation and tracking for emergency responders [79]. It is also important to build an indoor navigation system that can track firefighters within a meter [80].

WLAN-based RSSI Fingerprinting can provide highly accurate position estimations [81]. However, its accuracy decreases when there are many environmental changes. The RSSI of WLAN is affected by the environment. Examples of obstacles that can cause fluctuations in RSSI are walls, ceilings, and people [15], [38]. The effect of walls and ceilings have been discussed in [82]-[84]. The effect of people on signal strength was investigated in [85] for $60 \mathrm{GHz}$ [86], $868 \mathrm{MHz}$, and [87] [88] $2.4 \mathrm{GHz}$. The result showed that people's presence in the Line of Sight (LOS) between the AP and the Mobile Device (MD) decreased the RSSI by $2 \mathrm{dBm}$ to 5 $\mathrm{dBm}$. This decline in RSSI could result in a position error of more than $2 \mathrm{~m}$. Hence, an adaptive IPS that can adapt to environmental changes, including user orientation [89] and people's presence [90], [91], is needed to improve the accuracy of IPS.

The question then becomes, how do we detect people around users inside a building? In this case, the user's MD can be used to detect the people around him/ her [92], while others in the MD neighborhood could be found based on many protocols of communication such as WLAN direct [93], WLAN aware [94], near-field communication (NFC) [95], sound waves [96], and Bluetooth [97]. These solutions are less practical because they require many sensors or devices and it is assumed that the people around the user have brought their MD in an active condition. If the people did not bring an MD or they did not enable the communication protocol, then, they cannot detect their neighbor. Operating this function on MD would also consume a lot of battery.

Alternative ways to use the device installed in the building, therefore, have to be found. One of the devices that can be used and has been widely installed in buildings is the Closed-circuit television (CCTV). A report mentioned that 245 million CCTVs had been installed in 2014, with 65 percent of them being installed in Asia [98]. A market report from www.marketsandmarkets.com estimated the total market of video surveillance applications to reach $\$ 25.43$ billion by 2016 . There are even more installed CCTVs in Kuala Lumpur than in Australia [99], and more than $30 \%$ of Malaysian buildings have 21-30 CCTVs [100].

CCTVs and image processing are an alternative technique to detect people around users, so no extra cost is needed and the accuracy of IPS can finally be improved. Generally, people counting in image processing are classified as direct or indirect [101], as shown in Fig. 7. The direct method can be divided into model-based and trajectory-clustering-based [102]. The direct method was done by segmenting and detecting each individual and then counting each using some classifiers [103]. The direct method is also called object detection.

People Counting Technique based on Image Processing

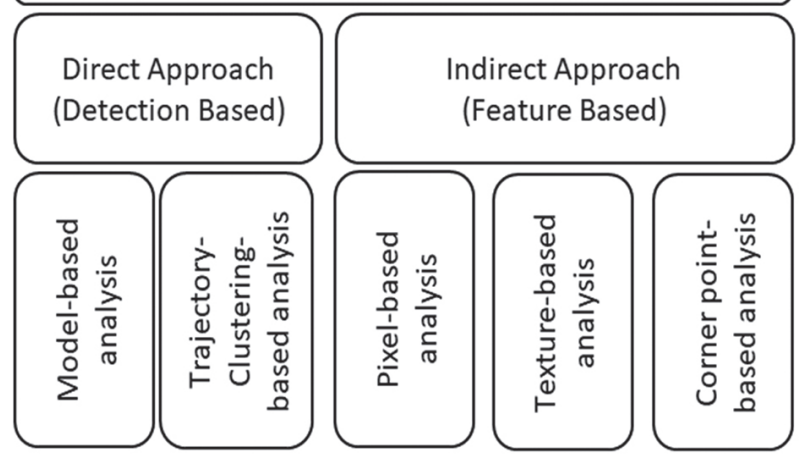

Fig. 7. People counting techniques in image processing

The model-based method detects every single person using a model or human shapes [104]. An example of the model-based approach can be seen in Fig. 8 , which used head shape detection. In contrast, the trajectory-clustering-based approach detects every independent motion [105]. In the indirect approach, the people can be counted based on some features in the foreground image, which are then processed using learning algorithms and statistical analysis [106]. It has been proven that detecting features are simpler than detecting persons. So the estimation process can be done using linear or non-linear regression functions such as support vector regression, as well as Bayesian and Gaussian regressions [107].

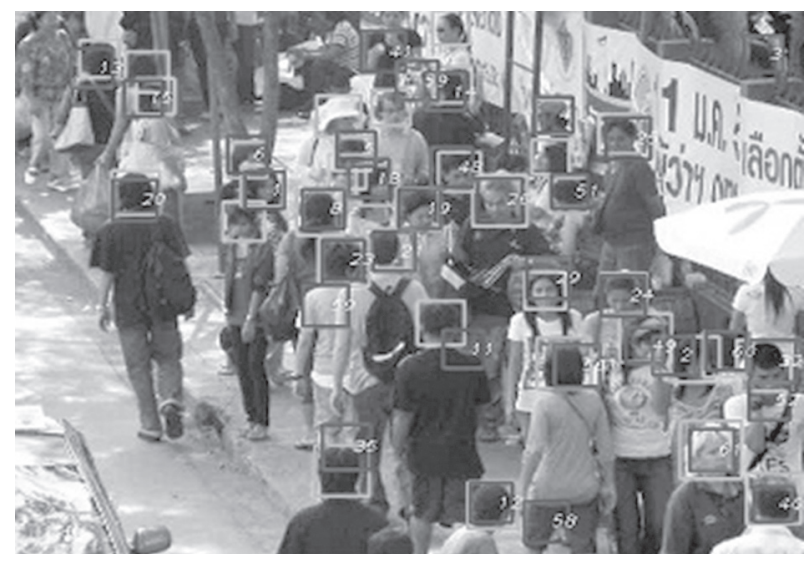

Fig. 8. People counting based on head detection [109]

Yoshinaga et al. [108] tried to count the number of pedestrians in real-time using a blob descriptor and neural networks. Chan et al. [107] used a mixture of dynamic-texture motion models to divide a crowd into homogeneous motion components. Their method extracted each seg- 
mented region into a set of holistic low-level features and then employed a Bayesian regression to map the features into the number of people per segment. This technique enabled the counting of crowds moving in different directions, but it was tested for an outdoor environment.

Another method proposed by Foroughi [103] was based on image retrieval, a simple global image descriptor, sparse representation, and random projection [110]. This method yielded better performance than regression methods, especially when the dataset was large. This technique, however, was also tested for outdoor environments.

Zhang [111] used a label distribution learning (LDL) strategy for crowd counting. Sivabalakrishnan [112] proposed a feedback update-by-detection scheme in foreground segmentation and attempted to balance between background noise removal and stationary people segmentation. A pair of collaborative Gaussian process models (GP) with different kernels was used by Zaydi [113] to estimate the number of people based on image processing. Ma [114] attempted to count the number of people in a video of them crossing a line using regression and local-level features. This method was able to estimate both cumulative and instantaneous counts.

A new concept in which an indoor positioning model based on WLAN fingerprinting and supported by image processing can be proposed to count the people around a user while a digital compass could be used to determine the user orientation. The data from image processing and the digital compass then serves as input for the WLAN IPS to improve the system accuracy without adding any extra cost, as seen in Fig. 9.

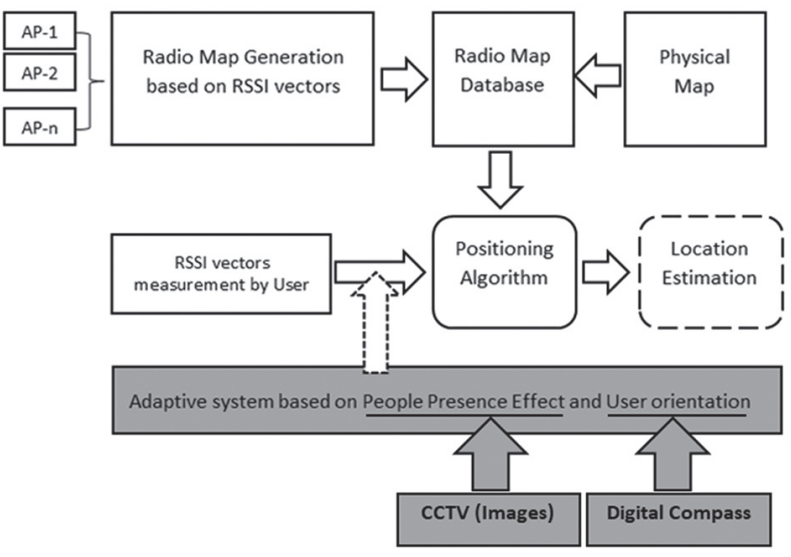

Fig. 9. Schematic diagram of the proposed concept to overcome people presence effect using WLAN fingerprinting and CCTV image

Finally, a new, accurate adaptive indoor positioning model based on WLAN Fingerprinting is proposed, using existing common devices (Access Points and CCTVs) installed in a building. This model was proposed to overcome the effect of any environmental change in a dynamic environment, especially the effect of people presence around a user and user orientation.

\section{CONCLUSION}

Several studies have combined image processing with WLAN fingerprinting to build an IPS. This review proposed dividing the combined techniques of WLAN fingerprinting and image processing into 3 . The first part examined the use of WLAN fingerprinting to support image positioning in the literature. The second part assessed works that have employed image processing to support WLAN fingerprinting positioning. Then, studies that had combined image processing and WLAN fingerprinting were reviewed to build IPS in the third method. This combination aims to improve system performance, especially the accuracy of the system. The second method gave more accurate position estimation, but it required more computational power and memory, as it mainly used the image processing technique to define user position.

The accuracy of IPS is significantly affected by the environment, especially the effect of people presence around the user and user orientation. WLAN fingerprinting and image processing techniques can be used in combination to solve this problem. A new concept for the future development of an indoor positioning model based on WLAN fingerprinting and supported by image processing was proposed for counting the people around a user while a digital compass could be used to determine the user orientation. The data from image processing and the digital compass could then serve as input for the WLAN IPS to improve system accuracy without adding any extra cost.

\section{ACKNOWLEDGEMENT}

This work has been supported by the UTM Grant (UTM-TDR 9.2(T1)). Hence, the authors would like to thank Universiti Teknologi Malaysia (UTM) for their support

\section{REFERENCES:}

[1] J. Raper, G. Gartner, H. Karimi, C. Rizos, "Applications of location-based services: a selected review", Journal of Location Based Services, Vol. 1, No. 2, 2007, pp. 89-111.

[2] J. Schiller, A. Voisard, "Location-Based Services", Elsevier, 2004.

[3] A. Basiri, T. Moore, C. Hill, P. Bhatia, "Challenges of Location-Based Services Market Analysis: Current Market Description", Progress in Location-Based Services 2014, G. Gartner and H. Huang, Springer International Publishing, 2015, pp. 273-282.

[4] Markets and markets, "Location Based Services (LBS) and Real Time Location Systems (RTLS) Market by Location, Technology, Software, Hardware, 
Service and Application Area - Global Forecast to 2021", 2016

[5] D. Dardari, P. Closas, P. M. Djuric, "Indoor Tracking: Theory, Methods, and Technologies", IEEE Transactions on Vehicular Technology, Vol. 64, No. 4, 2015 , pp. $1263-1278$.

[6] A. Dasgupta, I. Singh, "Inside A Big Building", Geospatial World, Vol. 6, No. 16, 2016.

[7] Z. Turgut, G. Z. G. Aydin, A. Sertbas, "Indoor Localization Techniques for Smart Building Environment", Procedia Computer Science, Vol. 83, 2016, pp. 1176-1181.

[8] L. Calderoni, M. Ferrara, A. Franco, D. Maio, “Indoor localization in a hospital environment using random forest classifiers", Expert Systems with Applications, Vol. 42, No. 1, 2015, pp. 125-134.

[9] S. A. Zekavat, H. Tong, J. Tan, "A novel wireless local positioning system for airport (indoor) security", Proceedings of SPIE 5403, Sensors, and Command, Control, Communications, and Intelligence (C3I) Technologies for Homeland Security and Homeland Defense III, Orlando, FL, USA, $15^{\text {th }}$ September 2004, pp. 522-533.

[10] B. Molina, E. Olivares, C. E. Palau, M. Esteve, "A multimodal fingerprint-based indoor positioning system for airports", IEEE Access, Vol. 6, 2018, pp. 10092-10106.

[11] N. Kawaguchi et al., "Underground positioning: Subway information system using WiFi location technology", Proceedings of the $10^{\text {th }}$ International Conference on Mobile Data Management: Systems, Services and Middleware, Taipei, Taiwan, 1820 December 2009, pp. 371-372.

[12] S. Woo et al., "Application of WiFi-based indoor positioning system for labor tracking at construction sites: A case study in Guangzhou MTR", Automation in Construction, Vol. 20, No. 1, 2011, pp. 3-13.

[13] P. Stephan, I. Heck, P. Krau, G. Frey, "Evaluation of Indoor Positioning Technologies under industrial application conditions in the SmartFactory $\mathrm{KL}$ based on EN ISO 9283", IFAC Proceedings Volumes, Vol. 42, No. 4, 2009, pp. 870-875.

[14] D. Zhang, F. Xia, Z. Yang, L. Yao, W. Zhao, “Localization Technologies for Indoor Human Tracking",
Proceedings of the $5^{\text {th }}$ International Conference on Future Information Technology, Busan, South Korea, 21-23 May 2010, pp. 1-6.

[15] Z. Farid, R. Nordin, M. Ismail, "Recent advances in wireless indoor localization techniques and system", Journal of Computer Networks and Communications, Vol. 2013, 2013.

[16] W. Zhang, J. Kosecka, "Image based localization in urban environments", Proceedings of the 3rd International Symposium on 3D Data Processing, Visualization, and Transmission, Chapel Hill, NC, USA, 14-16 June 2006, pp. 33-40.

[17] Y. Shu, C. Bo, G. Shen, C. Zhao, L. Li, F. Zhao, “Magicol: Indoor Localization Using Pervasive Magnetic Field and Opportunistic WiFi Sensing", IEEE Journal on Selected Areas in Communications, Vol. 33, No. 7, 2015, pp. 1443-1457.

[18] J. N. Moutinho, R. E. Araújo, D. Freitas, "Indoor localization with audible sound-Towards practical implementation", Pervasive and Mobile Computing, Vol. 29, 2016, pp. 1-16.

[19] G. Lu, Y. Yan, L. Ren, P. Saponaro, N. Sebe, C. Kambhamettu, "Where am i in the dark: Exploring active transfer learning on the use of indoor localization based on thermal imaging", Neurocomputing, Vol. 173, 2016, pp. 83-92.

[20] W. Yao, L. Ma, "Research and Application of Indoor Positioning Method Based on Fixed Infrared Beacon", Proceedings of the $37^{\text {th }}$ Chinese Control Conference, Wuhan, China, 25-27 July 2018, pp. 5375-5379.

[21] R. Mautz, S. Tilch, "Survey of optical indoor positioning systems", Proceedings of the International Conference on Indoor Positioning and Indoor Navigation, Guimaraes, Portugal, 21-23 September 2011, pp. 1-7.

[22] Y. Zhuang et al., "A survey of positioning systems using visible LED lights", IEEE Communications Surveys \& Tutorials, Vol. 20, No. 3, 2018, pp. 1963-1988.

[23] S. Cincotta, C. He, A. Neild, J. Armstrong, "Indoor Visible Light Positioning: Overcoming the Practical Limitations of the Quadrant Angular Diversity Aperture Receiver (QADA) by Using the Two-Stage QADA-Plus Receiver", Sensors, Vol. 19, No. 4, 2019, p. 956. 
[24] D. Han, S. Jung, S. Lee, "A sensor fusion method for Wi-Fi-based indoor positioning", ICT Express, Vol. 2, No. 2, 2016, pp. 71-74.

[25] P. Bahl, V. N. Padmanabhan, "RADAR: An in-building RF-based user location and tracking system", Proceedings IEEE INFOCOM 2000, Conference on Computer Communications, 19 th $^{\text {th }}$ Annual Joint Conference of the IEEE Computer and Communications Societies, Tel Aviv, Israel, 26-30 March 2000, pp. 775-784.

[26] G. Kul, T. Özyer, B. Tavli, "IEEE 802.11 WLAN based Real Time Indoor Positioning: Literature Survey and Experimental Investigations", Procedia Computer Science, Vol. 34, 2014, pp. 157-164.

[27] R. Faragher, R. Harle, "Location Fingerprinting With Bluetooth Low Energy Beacons", IEEE Journal on Selected Areas in Communications, Vol. 33, No. 11, 2015, pp. 2418-2428.

[28] X. Hu, L. Cheng, G. Zhang, "A Zigbee-based localization algorithm for indoor environments", Proceedings of the 2011 International Conference on Computer Science and Network Technology, Harbin, China, 24-26 December 2011, pp. 1776-1781.

[29] V. Bianchi, P. Ciampolini, I. De Munari, “RSSI-Based Indoor Localization and Identification for ZigBee Wireless Sensor Networks in Smart Homes", IEEE Transactions on Instrumentation and Measurement, Vol. 68, No. 2, 2019, pp. 566-575.

[30] C. Tsirmpas, A. Rompas, O. Fokou, D. Koutsouris, "An indoor navigation system for visually impaired and elderly people based on Radio Frequency Identification (RFID)", Information Sciences, Vol. 320,2015 , pp. 288-305.

[31] V. Moghtadaiee, A. G. Dempster, S. Lim, "Indoor localization using $\mathrm{fm}$ radio signals: A fingerprinting approach", Proceedings of the 2011 International Conference on Indoor Positioning and Indoor Navigation, Guimaraes, Portugal, 21-23 September 2011, pp. 1-7.

[32] K. Witrisal, S. Hinteregger, J. Kulmer, E. Leitinger, and P. Meissner, "High-accuracy Positioning for Indoor Applications: RFID, UWB, 5G, and beyond", Proceedings of the IEEE International Conference on RFID, Orlando, FL, USA, 3-5 May 2016, pp. 1-7.
[33] G. Schroeer, "A Real-Time UWB Multi-Channel Indoor Positioning System for Industrial Scenarios", Proceedings of the International Conference on Indoor Positioning and Indoor Navigation, Nantes, France, 24-27 September 2018, pp. 1-5.

[34] C. Yang, H.-R. Shao, "WiFi-based indoor positioning", IEEE Communications Magazine, Vol. 53, No. 3, 2015, pp. 150-157.

[35] Q. Pu, M. Zhou, F. Zhang, Z. Tian, "Group Power Constraint Based Wi-Fi Access Point Optimization for Indoor Positioning", KSII Transactions on Internet \& Information Systems, Vol. 12, No. 5, 2018, pp. 1951-1972.

[36] B. Jang, H. Kim, "Indoor Positioning Technologies Without Offline Fingerprinting Map: A Survey", IEEE Communications Surveys \& Tutorials, Vol. 21, No. 1, 2018, pp. 508-525.

[37] Y. Tao, L. Zhao, "A Novel System for WiFi Radio Map Automatic Adaptation and Indoor Positioning", IEEE Transactions on Vehicular Technology, Vol. 67, No. 11, 2018, pp. 10683-10692.

[38] S. He, S.-H. G. Chan, "Wi-Fi fingerprint-based indoor positioning: Recent advances and comparisons", IEEE Communications Surveys \& Tutorials, Vol. 18, No. 1, 2016, pp. 466-490.

[39] K. Maneerat, K. Kaemarungsi, "RoC: Robust and Low-Complexity Wireless Indoor Positioning Systems for Multifloor Buildings Using Location Fingerprinting Techniques", Mobile Information Systems, Vol. 2019, 2019.

[40] J. Hu, D. Liu, Z. Yan, H. Liu, “Experimental Analysis on Weight K-Nearest Neighbor Indoor Fingerprint Positioning", IEEE Internet of Things Journal, Vol. 6, No. 1, 2019, pp. 891-897.

[41] T. P. Thanh, K. D. Trung, L. L. Thi, Y. P. Ngoc, L. N. Hung, "Toward to a hybrid mobile object localization method based on WiFi and image", presented at the The $6^{\text {th }}$ Vietnamese Conference FAIR - Fundamental and Applied IT Research, Vietnam, 2013

[42] A. Kitanov, S. Bisevac, I. Petrovic, "Mobile robot self-localization in complex indoor environments using monocular vision and 3D model", Proceedings of the IEEE/ASME international conference 
on advanced intelligent mechatronics, Zurich, Switzerland, 4-7 September 2007, pp. 1-6.

[43] G. M. Mendoza-Silva, J. Torres-Sospedra, J. Huerta, "A Meta-Review of Indoor Positioning Systems", Sensors, Vol. 19, No. 20, 2019, p. 4507.

[44] A. Khalajmehrabadi, N. Gatsis, D. Akopian, "Modern WLAN fingerprinting indoor positioning methods and deployment challenges", IEEE Communications Surveys \& Tutorials, Vol. 19, No. 3, 2017, pp. 1974-2002.

[45] J. Kim, H. Jun, "Vision-based location positioning using augmented reality for indoor navigation", IEEE Transactions on Consumer Electronics, Vol. 54, No. 3, 2008, pp. 954-962.

[46] A. J. Ruiz-Ruiz, P. E. Lopez-de-Teruel, O. Canovas, "A multisensor LBS using SIFT-based 3D models", Proceedings of the International Conference on Indoor Positioning and Indoor Navigation, Sydney, NSW, Australia, 13-15 November 2012, pp. 1-10.

[47] A. J. Ruiz-Ruiz, O. Canovas, P. E. Lopez-de-Teruel, "A Multisensor Architecture Providing Locationbased Services for Smartphones", Mobile Netw Appl, Vol. 18, No. 3, 2013, pp. 310-325.

[48] S. Papaioannou, H. Wen, A. Markham, N. Trigoni, "Fusion of radio and camera sensor data for accurate indoor positioning", Proceedings of the $11^{\text {th }}$ International Conference on Mobile Ad Hoc and Sensor Systems, Philadelphia, PA, USA, 28-30 October 2014, pp. 109-117.

[49] S. Ito, F. Endres, M. Kuderer, G. D. Tipaldi, C. Stachniss, W. Burgard, "W-RGB-D: Floor-plan-based indoor global localization using a depth camera and WiFi", Proceedings of the IEEE International Conference on Robotics and Automation, Hong Kong, China, 31 May - 7 June 2014, pp. 417-422.

[50] W. Jiang, Z. Yin, "Indoor localization with a signal tree", Proceedings of the $18^{\text {th }}$ International Conference on Information Fusion, Washington, DC, USA, 6-9 July 2015, pp. 1724-1731.

[51] X. He, D. Aloi, J. Li, "Portable 3D visual sensor based indoor localization on mobile device", Proceedings of the $13^{\text {th }}$ IEEE Annual Consumer Communications \& Networking Conference, Las Vegas, NV, USA, 9-12 January 2016, pp. 1125-1128.
[52] J. Jiao, Z. Deng, L. Xu, F. Li, "A Hybrid of Smartphone Camera and Basestation Wide-area Indoor Positioning Method", KSII Transactions on Internet and Information Systems (TIIS), Vol. 10, No. 2, 2016, pp. 723-743.

[53] H. Bay, T. Tuytelaars, L. V. Gool, "SURF: Speeded Up Robust Features", Proceedings of the European Conference on Computer Vision, Graz, Austria, 7-13 May 2006, pp. 404-417.

[54] Z. Wang, J. Huang, Y. Tang, Z. Shi, R. Lan, "Indoor Location Fusion Algorithm Based on Smartphone", Proceedings of the $7^{\text {th }}$ International Conference on Digital Home, Guilin, China, 30 November -1 December 20, pp. 300-304.

[55] Z. Wang, P. Sokliep, C. Xu, J. Huang, L. Lu, Z. Shi, “Indoor Position Algorithm Based on the Fusion of Wifi and Image", Proceedings of the $11^{\text {th }}$ International Conference on Advanced Computational Intelligence, Guilin, China, 7-9 June 2019, pp. 212-216.

[56] A. Krizhevsky, I. Sutskever, G. E. Hinton, "Imagenet classification with deep convolutional neural networks", Proceedings of the $25^{\text {th }}$ International Conference on Neural Information Processing Systems, Lake Tahoe, NV, USA, December 2012, pp. 1097-1105.

[57] Z. S. Hashemifar, C. Adhivarahan, A. Balakrishnan, K. Dantu, "Augmenting Visual SLAM with Wi-Fi Sensing For Indoor Applications", arXiv, No. 1903.06687, 2019.

[58] S. Yang, Q. Sun, X. Dong, J. Yuan, "A Novel SLAM Method Using Wi-Fi Signal Strength and RGB-D Images", Proceedings of the IEEE $8^{\text {th }}$ Annual International Conference on CYBER Technology in Automation, Control, and Intelligent Systems, Tianjin, China, 19-23 July 2018, pp. 540-545.

[59] P. Mirowski, R. Palaniappan, T. K. Ho, “Depth camera SLAM on a low-cost WiFi mapping robot", Proceedings of the IEEE International Conference on Technologies for Practical Robot Applications, Woburn, MA, USA, 23-24 April 2012, pp. 1-6.

[60] J. C. Ching, C. Domingo, K. Iglesia, C. Ngo, N. Chua, "Mobile Indoor Positioning Using Wi-fi Localization and Image Processing", Proceedings in Information and Communications Technology, Vol 7., Springer, Tokyo, pp. 242-256. 
[61] J. Niu, K. V. Ramana, B. Wang, J. J. P. C. Rodrigues, "A Robust Method for Indoor Localization Using Wi-Fi and SURF Based Image Fingerprint Registration", Proceedings of the International Conference on Ad-Hoc Networks and Wireless, Benidorm, Spain, 22-27 June, pp. 346-359.

[62] Y. Hou, G. Sum, B. Fan, "The indoor wireless location technology research based on WiFi", Proceedings of the $10^{\text {th }}$ International Conference on Natural Computation, Xiamen, China, 19-21 August 2014, pp. 1044-1049.

[63] F. Gu, J. Niu, L. Duan, "WAIPO: A fusion-based collaborative indoor localization system on smartphones", IEEE/ACM Transactions on Networking, Vol. 25, No. 4, 2017, pp. 2267-2280.

[64] Y. Zheng, G. Shen, L. Li, C. Zhao, M. Li, F. Zhao, "Travi-navi: Self-deployable indoor navigation system", IEEE/ACM transactions on networking, Vol. 25, No. 5, 2017, pp. 2655-2669.

[65] M. U. Ali, S. Hur, Y. Park, "LOCALI: Calibration-Free Systematic Localization Approach for Indoor Positioning", Sensors, Vol. 17, No. 6, 2017, p. 1213.

[66] M. U. Ali, S. Hur, Y. Park, "Wi-Fi-based effortless indoor positioning system using loT sensors", Sensors, Vol. 19, No. 7, 2019, p. 1496.

[67] K. Hattori et al., "Hybrid Indoor Location Estimation System Using Image Processing and WiFi Strength", Proceedings of the International Conference on Wireless Networks and Information Systems, Shanghai, China, 28-29 December 2009, pp. 406-411.

[68] N. Lemieux, H. Lutfiyya, "WHLocator: hybrid indoor positioning system", Proceedings of the International Conference on Pervasive Services, London, UK, 13-17 July 2009, pp. 55-64.

[69] J. Teng, B. Zhang, J. Zhu, X. Li, D. Xuan, Y. F. Zheng, "Ev-loc: integrating electronic and visual signals for accurate localization", IEEE/ACM Transactions on Networking, Vol. 22, No. 4, 2014, pp. 1285-1296.

[70] P. Levchev, M. N. Krishnan, C. Yu, J. Menke, A. Zakhor, "Simultaneous fingerprinting and mapping for multimodal image and WiFi indoor positioning", Proceedings of the International Conference on Indoor Positioning and Indoor Navigation, Busan, South Korea, 27-30 October 2014, pp. 442-450.
[71] W. M. Y. W. Bejuri, M. M. Mohamad, "Performance Analysis of Grey-World-based Feature Detection and Matching for Mobile Positioning Systems", Sensing and Imaging, Vol. 15, No. 1, 2014, p. 95.

[72] H. Xu, Z. Yang, Z. Zhou, L. Shangguan, K. Yi, Y. Liu, "Enhancing wifi-based localization with visual clues", Proceedings of the ACM International Joint Conference on Pervasive and Ubiquitous Computing, Osaka, Japan, 7-11 September 2015, pp. 963-974.

[73] J. Jiao, F. Li, Z. Deng, W. Ma, "A smartphone camerabased indoor positioning algorithm of crowded scenarios with the assistance of deep CNN", Sensors, Vol. 17, No. 4, 2017, p. 704.

[74] J. Jiao, F. Li, W. Tang, Z. Deng, J. Cao, "A hybrid fusion of wireless signals and RGB image for indoor positioning", International Journal of Distributed Sensor Networks, Vol. 14, No. 2, 2018, pp. 1-11.

[75] M. D. Redžić, C. Laoudias, I. Kyriakides, "Image and WLAN Bimodal Integration for Indoor User Localization", IEEE Transactions on Mobile Computing, 2019 (in press).

[76] J. Jiao, Z. Deng, Q. A. Arain, F. Li, "Smart Fusion of Multi-sensor Ubiquitous Signals of Mobile Device for Localization in GNSS-Denied Scenarios", Wireless Personal Communications, 2018, pp. 1-17.

[77] The National 911 Program, "Next Generation 911 (NG911) Standards Identification and Review", March 2015.

[78] U.S. Department of Transportation, "Intelligent Transportation Systems - Next-Generation 911", 2009.

[79] U.S. Department of Homeland Security, "Precision Outdoor and Indoor Navigation and Tracking for Emergency Responders (POINTER)", 2016.

[80] M. Harris, "How New Indoor Navigation Systems Will Protect Emergency Responders", IEEE Spectrum, August 2013.

[81] I. H. Alshami, N. A. A. Salleh, S. Sahibuddin, "Automatic WLAN fingerprint radio map generation for accurate indoor positioning based on signal path loss model", ARPN Journal of Engineering and Applied Sciences, Vol. 10, No. 23, 2015, pp. 17930-17936. 
[82] C. B. Andrade, R. P. F. Hoefel, "IEEE 802.11 WLANs: A comparison on indoor coverage models", Proceedings of the Canadian Conference on Electrical and Computer Engineering, Calgary, AB, Canada, 2-5 May 2010, pp. 1-6.

[83] T. Sadiki, P. Paimblanc, "Modelling New Indoor Propagation Models for WLAN Based on Empirical Results", Proceedings of the $11^{\text {th }}$ International Conference on Computer Modelling and Simulation, Cambridge, UK, 25-27 March 2009, pp. 585-588.

[84] J. A. Santana, E. Macías, Á. Suárez, D. Marrero, V. Mena, "Adaptive estimation of WiFi RSSI and its impact over advanced wireless services", Mobile Networks and Applications, Vol. 22, No. 6, 2017, pp. 1100-1112.

[85] P. Karadimas, B. Allen, P. Smith, “Human body shadowing characterization for $60-\mathrm{GHz}$ indoor shortrange wireless links", IEEE Antennas and Wireless Propagation Letters, Vol. 12, 2013, pp. 1650-1653.

[86] E. Ben Hamida, G. Chelius, "Investigating the impact of human activity on the performance of wireless networks-An experimental approach", Proceedings of the IEEE International Symposium on 'A World of Wireless, Mobile and Multimedia Networks', Montreal, QC, Canada, 14-17 June 2010, pp. 1-8.

[87] I. H. Alshami, N. A. Ahmad, S. Sahibuddin, "People effects on WLAN-Based IPS' accuracy experimental preliminary results", Proceedings of the $8^{\text {th }}$ Malaysian Software Engineering Conference, Langkawi, Malaysia, 23-24 September 2014 pp. 206-209.

[88] J. S. Turner et al., "The study of human movement effect on Signal Strength for indoor WSN deployment", Proceedingso $f$ the IEEE Conference on Wireless Sensor, Kuching, Malaysia, 2-4 December 2013, pp. 30-35.

[89] Firdaus, N. A. Ahmad, S. Sahibuddin, "Adapted WLAN Fingerprint Indoor Positioning System (IPS) Based on User Orientations", Proceedings of the International Conference of Reliable Information and Communication Technology, Johor Bahru, Malaysia, 23-24 April 2017, pp. 226-236.

[90] Firdaus, N. A. Ahmad, S. Sahibuddin, "Effect of People Around User to WLAN Indoor Positioning System Accuracy", Proceedings of the Palestin- ian International Conference on Information and Communication Technology, Gaza City, Palestinian Authority, 8-9 May 2017, pp. 17-21.

[91] A. Booranawong, K. Sengchuai, N. Jindapetch, "Implementation and test of an RSSI-based indoor target localization system: Human movement effects on the accuracy", Measurement, Vol. 133, 2019, pp. 370-382.

[92] H. Li, H. Lu, L. Shou, G. Chen, K. Chen, "In Search of Indoor Dense Regions: An Approach Using Indoor Positioning Data", IEEE Transactions on Knowledge and Data Engineering, Vol. 30, No. 8, 2018, pp. 1481-1495.

[93] N. Banerjee, S. Agarwal, P. Bahl, R. Chandra, A. Wolman, M. Corner, "Virtual compass: relative positioning to sense mobile social interactions", Proceedings of the International Conference on Pervasive Computing, Helsinki, Finland, 17-20 May 2010, pp. $1-21$.

[94] Wi-Fi Alliance, "Wi-Fi Aware: Discover the World Nearby", July 2015.

[95] J. Jun et al., "Social-Loc: Improving indoor localization with social sensing", Proceedings of the $11^{\text {th }}$ ACM Conference on Embedded Networked Sensor Systems, 2013, Roma, Italy, 11-15 November 2013, pp. 1-14.

[96] H. Liu et al., "Push the limit of WiFi based localization for smartphones", Proceedings of the $18^{\text {th }}$ Annual International Conference on Mobile Computing and Networking, Istanbul, Turkey, 22-26 August 2012, pp. 305-316.

[97] S. Liu, Y. Jiang, A. Striegel, "Face-to-Face Proximity EstimationUsing Bluetooth On Smartphones", IEEE Transactions on Mobile Computing, Vol. 13, No. 4, 2014, pp. 811-823.

[98] SDM Magazine, "Rise of Surveillance Camera Installed Base Slows", May 2016, http://www.sdmmag.com/articles/92407-rise-of-surveillancecamera-installed-base-slows (accessed: 2017)

[99] A. A. Bakar, "More CCTV cameras in $\mathrm{KL}$ than in Australia", Free Malaysia Today, May 2016, http:// www.freemalaysiatoday.com/category/nation/2016/05/30/more-cctv-cameras-in-kl-thanin-australia/ (accessed: 2017) 
[100] A. S. Ali, S. A. F. Al-Zawawi, "The Effectiveness of Closed-Circuit Television (CCTV) In Malaysian Commercial Buildings", Presented at the Symposium on Sustainable Construction Material and Building System, Kuala Lumpur, 2009.

[101] D. Conte, P. Foggia, G. Percannella, F. Tufano, M. Vento, "A method for counting people in crowded scenes", Proceedings of the $7^{\text {th }}$ IEEE International Conference on Advanced Video and Signal Based Surveillance, Boston, MA, USA, 29 August -1 September 2010, pp. 225-232.

[102] S. A. M. Saleh, S. A. Suandi, H. Ibrahim, "Recent survey on crowd density estimation and counting for visual surveillance", Engineering Applications of Artificial Intelligence, Vol. 41, 2015, pp. 103-114.

[103] H. Foroughi, N. Ray, H. Zhang, "People counting with image retrieval using compressed sensing", Proceedings of the IEEE International Conference on Acoustics, Speech and Signal Processing, Florence, Italy, 4-9 May 2014, pp. 4354-4358.

[104] K. Chen, C. C. Loy, S. Gong, T. Xiang, "Feature Mining for Localised Crowd Counting", Proceedings of the British Machine Vision Conference, Surrey, UK, 3-7 September 2012, p. 3.

[105] V. Rabaud, S. Belongie, “Counting crowded moving objects", Proceedings of the IEEE Computer Society Conference on Computer Vision and Pattern Recognition, New York, NY, USA, 17-22 June 2006, pp. 705-711.

[106] Z. Zhang, M. Li, "Crowd density estimation based on statistical analysis of local intra-crowd motions for public area surveillance", Optical Engineering, Vol. 51, No. 4, 2012, pp.1-13.

[107] A. B. Chan, N. Vasconcelos, "Counting people with low-level features and Bayesian regression",
IEEE Transactions on Image Processing, Vol. 21, No. 4, 2012, pp. 2160-2177.

[108] S. Yoshinaga, A. Shimada, R. Taniguchi, "Realtime people counting using blob descriptor", Procedia-Social and Behavioral Sciences, Vol. 2, No. 1, 2010, pp. 143-152.

[109] I. Ali, M. N. Dailey, "Head plane estimation improves the accuracy of pedestrian tracking in dense crowds", Proceedings of the $11^{\text {th }}$ International Conference on Control Automation Robotics \& Vision, Singapore, Singapore, 7-10 December 2010, pp. 2054-2059.

[110] H. Foroughi, N. Ray, H. Zhang, "Robust people counting using sparse representation and random projection", Pattern Recognition, Vol. 48, No. 10, 2015, pp. 3038-3052.

[111] Z. Zhang, M. Wang, X. Geng, "Crowd counting in public video surveillance by label distribution learning", Neurocomputing, Vol. 166, 2015, pp. 151-163.

[112] M. Sivabalakrishnan, K. Shanthi, "Person Counting System Using EFV Segmentation and Fuzzy Logic", Procedia Computer Science, Vol. 50, 2015, pp. 572-578.

[113] Z. Q. H. Al-Zaydi, D. L. Ndzi, Y. Yang, M. L. Kamarudin, "An adaptive people counting system with dynamic features selection and occlusion handling", Journal of Visual Communication and Image Representation, Vol. 39, 2016, pp. 218-225.

[114] Z. Ma, A. B. Chan, "Counting People Crossing a Line Using Integer Programming and Local Features", IEEE Transactions on Circuits and Systems for Video Technology, Vol. 26, No. 10, 2016, pp. 1955-1969. 